Acta vet. scand. $1973,14,233-244$.

From the Department of Pathology and the Laboratory of Electron Microscopy, College of Veterinary Medicine, Helsinki, Finland.

\title{
ON THE ULTRASTRUCTURE OF EPITHELIAL CELLS IN BILE DUCTS OF CATTLE CHRONICALLY INFECTED WITH FASCIOLA HEPATICA*
}

By

\author{
Timo Rahko
}

RAHKO, TIMO: On the ultrastructure of epithelial cells in bile ducts of cattle chronically infected with Fasciola hepatica. Acta vet. scand. 1973, 14, 233-244. - This paper describes briefly the normal ultrastructure of bile-duct epithelial cells in cattle and the main ultrastructural alterations produced in them by chronic infection with Fasciola hepatica. The studies showed only inconsiderable abnormalities in the ultrastructure of the epithelium in infections of a low degree as also during the recovery phase of the disease. On the other hand, in heavily infected livers pronounced ultrastructural alterations were seen in the surface epithelium of the main intrahepatic bile ducts invaded by the flukes. In such areas the intercellular spaces were filled with dense homogeneous material, and intact desmosomes and junctional complexes were not regularly seen, which indicates that foreign material may leak into the bile. The extracellular material was probably composed of albumin, and the significance of the present results regarding the etiology of hypoalbuminaemia during chronic fascioliasis is discussed.

electron microscopy; bileducts; fascioliasis;

c at $\mathrm{tl}$ e.

Chronic infection of animals with Fasciola hepatica may produce a clinical disease, the main symptoms of which are anaemia, hypoalbuminaemia and a loss of condition (Sinclair 1967, Dawes $\&$ Hughes 1970). Though the anaemia and hypoalbuminaemia caused by fascioliasis have been the subjects of several studies,

* Supported by grants from the National Research Council for Medical Sciences and the Finnish Veterinary Medical Foundation. 
their etiology is still partly unknown. The clinical investigations by Dargie and his co-workers (Dargie et al. 1968, Dargie \& Mulligan 1970, 1971) have shown that the etiology of hypoalbuminaemia cannot be completely explained by a loss of whole blood into the bile.

Electron microscopical studies on experimentally infected mice (Rahko 1971) suggested a further explanation of the anaemia and hypoalbuminaemia produced by fascioliasis. It was observed that during chronic fascioliasis the intercellular spaces in the bile-duct epithelium of the mouse became enlarged and filled with foreign substances of probably proteinaceous nature. Further, the intercellular connections between superficial epithelial cells became ruptured, indicating that the extracellular material may leak into the bile.

The purpose of the present study was to investigate, whether ultrastructural alterations analogous to those shown in experimental fascioliasis (Rahko 1971) may be observed in the bileduct epithelium of cattle naturally infected with $F$. hepatica.

\section{MATERIAL AND METHODS}

The material was collected at the slaughter-house of Karjakunta in Helsinki during February and March 1971 and consisted of tissue specimens from the bile-duct walls of five cows chronically infected with $F$. hepatica and of seven uninfected cows examined as controls. Livers showing gross or microscopic evidence of infection with $\mathrm{D}$. dendriticum were excluded.

Immediately after the slaughter of the animals (i.e. about 30 min. after their death) several tissue specimens were taken and placed without delay in glutaraldehyde solution. The specimens were removed from three portions of the bile ducts: from the middle portion of the common bile duct and from the main intrahepatic bile ducts in the hilus area and in the left lobe of the liver. The tissue blocks were fixed for 2-6 hrs. in chilled $2.5 \%$ glutaraldehyde in $0.1 \mathrm{M}$ phosphate buffer, washed in buffered $10 \%$ sucrose, postfixed in chilled $1 \%$ osmium tetroxide in the same buffer for $2 \mathrm{hrs}$, dehydrated in ethanol, and embedded in Epon (Luft 1961). Thin sections were cut with glass knives using an ultramicrotome (Ultrotome), and those showing silver or gold interference colour were mounted on copper grids, stained with aqueous uranyl acetate (Kay 1965) and examined 
with an Akashi electron microscope in the Laboratory of Electron Microscopy, College of Veterinary Medicine. Sections approx. $1-$ $2 \mu$ thick cut with the ultramicrotome were stained with acidic $0.1 \%$ toluidine blue (Setoguti 1969) for the selection of suitable tissue blocks by light microscopy.

After careful macroscopical examination, tissue specimens were selected from the main intrahepatic bile ducts of the livers and prepared, according to routine laboratory procedures, for light microscopical studies in which the histological alterations in the bile-duct walls were studied. The three histological patterns mentioned in the following text are described in detail in a previous paper (Rahko 1971).

\section{Control animals}

\section{RESULTS}

Since the time elapsing between the slaughter of the animals and the fixation of the tissue specimens produced some changes in the structure of the epithelial cells, only those ultrastructural characteristics were studied which corresponded to alterations earlier observed to be caused by experimental fascioliasis in the mouse (Rahko 1971).

The ultrastructure of epithelial cells in different sections of the bile ducts appeared similar, but the superficial epithelial cells differed from those in the glands, which were present in the common bile duct and in the main intrahepatic bile ducts in the hilus area of the liver. The cells in the surface epithelium (Fig. 1) showed elongated nuclei with mostly marginal chromatin, varying amounts of different cytoplasmic organelles, such as mitochondria, free or attached ribosomes and structures of endoplasmic reticulum, but only occasionally bodies identified as mucin granules. Glycogen granules were not seen.

The outlines of the cells were regular, except at the luminal surface carrying microvilli, and the cells were regularly connected by desmosomes and junctional complexes. The intercellular spaces were usually narrow, sometimes widened but always free from homogeneous electron-opaque material (Fig. 1). The glandular epithelial cells and the goblet cells differed in that their cytoplasm contained numerous mucin granules surrounded by smooth membranes. 

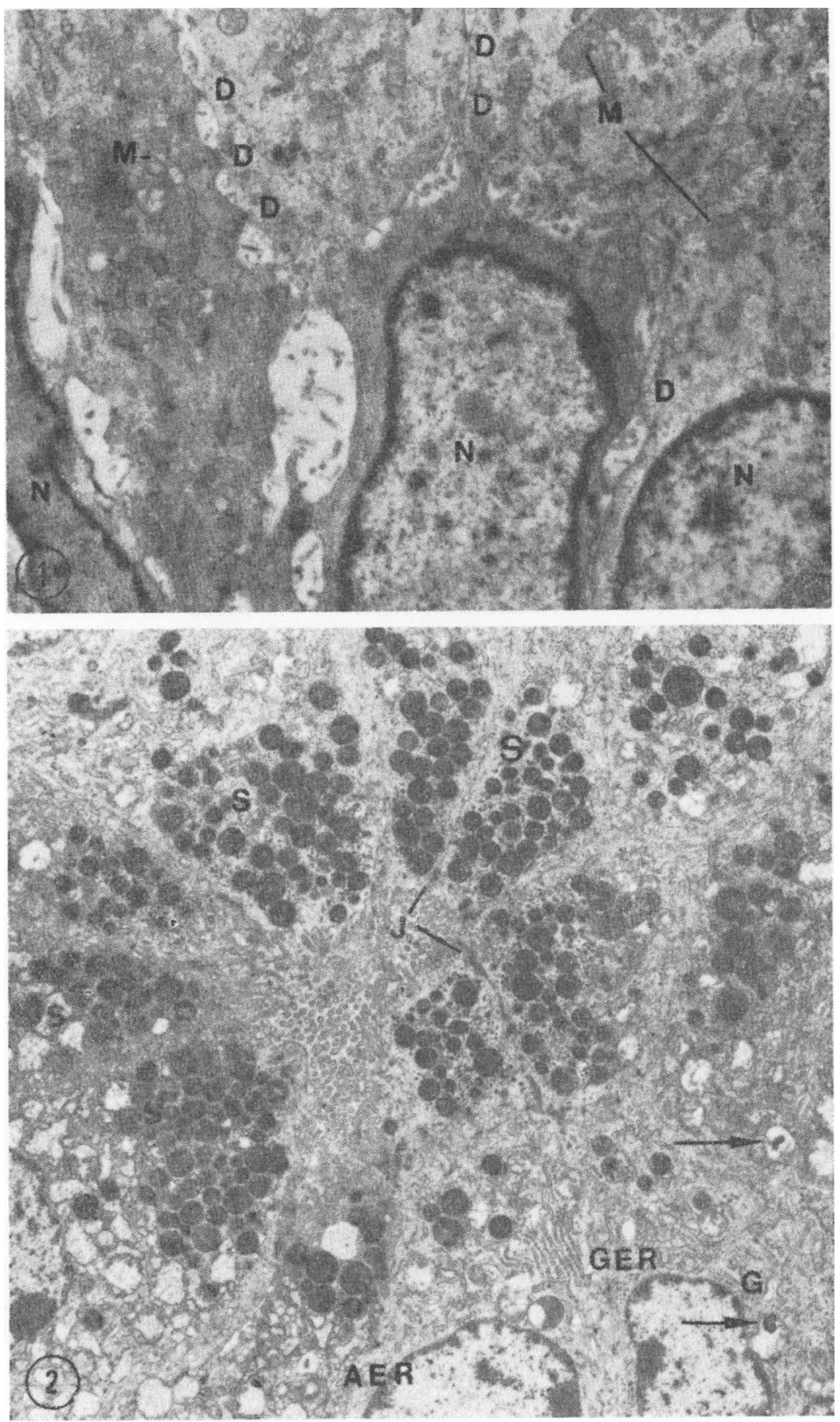


\section{Fascioliasis}

Common bile duct. The general arrangement of superficial and glandular (Fig. 2) epithelial cells appeared fairly normal in all the cases studied. Some epithelial cells in the surface epithelium showed irregular microvilli (Fig. 3) or were devoid of microvilli, and electron-opaque lamellar bodies were observed in the lumina of a few mitochondria (Fig. 2). The intercellular connections and spaces were normal (Fig. 3). Traumatic lesions were not seen.

Main intrahepatic bile ducts. In two animals the ultrastructural features of the epithelial cells appeared fairly similar to those in the common bile duct. These livers were only moderately infected, and light microscopical tissue specimens showed slight alterations typical of the first and second histological patterns (Rahko 1971). In three animals more distinct ultrastructural abnormalities were seen (Figs. 4-9). One of these animals showed the third histological pattern, and electron microscopy revealed indications of slight degeneration of epithelial cells (Fig. 5) and the presence of mucin-producing glands also in small bile ducts in the left lobe of the liver (Fig. 6).

Two livers carried numerous flukes in the bile ducts, and pronounced changes typical of the second histological pattern were seen in the light microscopical tissue specimens. In addition to traumatic (Fig. 4) and degenerative (Fig. 7) changes, electron microscopy of tissue specimens from areas harbouring flukes showed that the spaces between the superficial epithelial cells

Fig u re 1. Control animal. Electron micrograph, showing parts of superficial epithelial cells in the common bile duct. The intercellular spaces are translucent, display some profiles of cytoplasmic processes and are sealed by desmosomes (D), N: Nucleus, M: Mitochondria. $\times 9,000$.

Figures 2-9 are electron micrographs of bile-duct epithelial cells in chronic fascioliasis.

Fig u r e 2. Glandular cells in the common bile duct, showing ultrastructural features comparable to those in control animals, except for the lamellar electron-opaque bodies (arrows) seen in the lumina of two mitochondria. The absence or the breakage of mitochondrial cristae was considered to be one of the post-mortal changes. AER: Agranular endoplasmic reticulum, GER: Granular endoplasmic reticulum, G: Golgi apparatus; J: Junctional complex; S: Mucin granules. $\times 6,000$. 

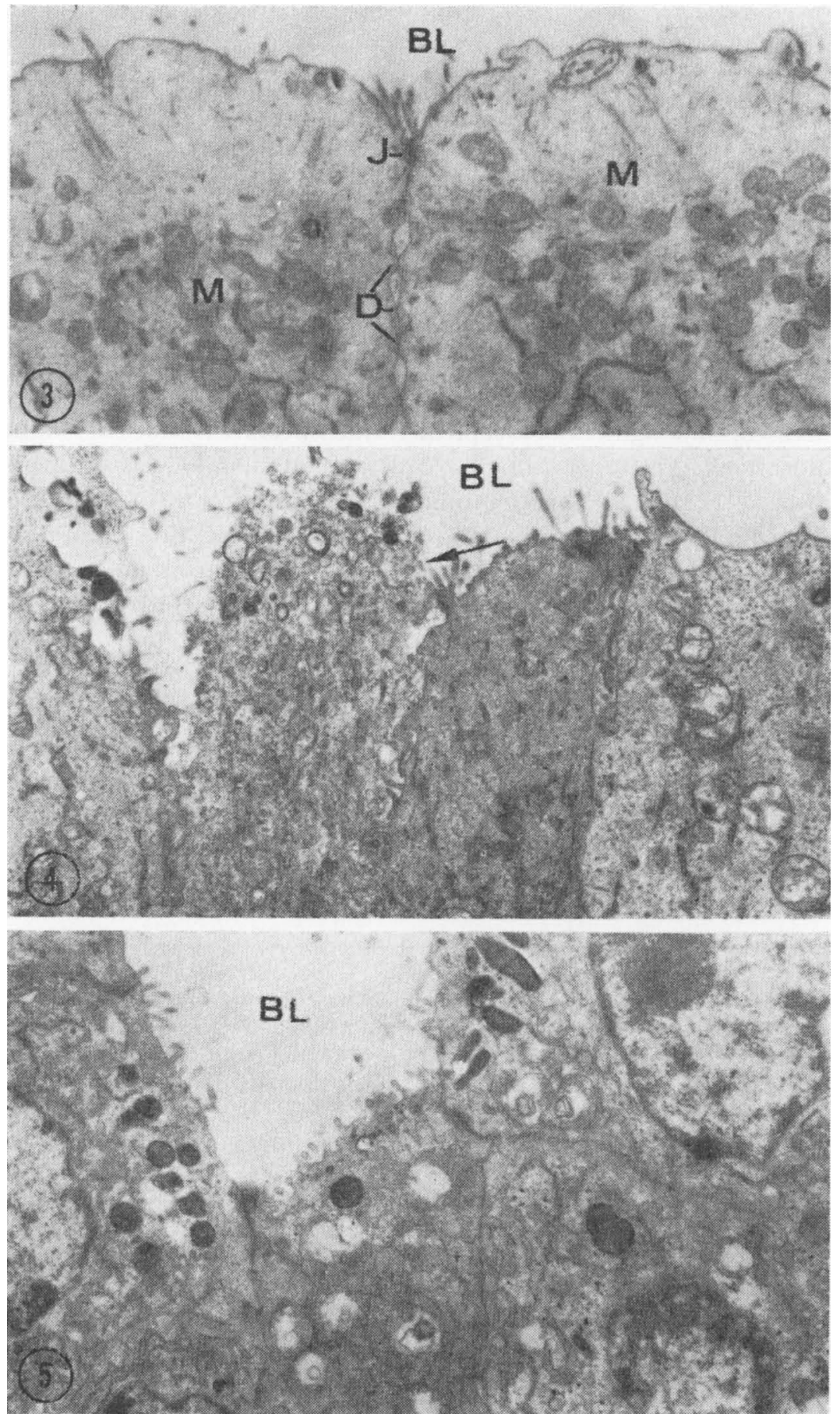
were dilated and contained dense material, and junctional complexes were not regularly seen (Figs. 8 and 9 ).

In such areas of the surface epithelium the cells showed irregular outlines, owing to irregular cytoplasmic processes projecting into the intercellular spaces (Fig. 8). Desmosomes were observed less frequently than normal between the cells and many cells were partly unattached. The junctional complexes were often ruptured and the homogeneous, moderately electron-opaque material filling the intercellular spaces appeared similar to that which had leaked into the lumina of the ducts (Fig. 9).

\section{DISCUSSION}

The normal ultrastructure of the epithelium in the bile ducts of cattle has not been described in the literature known to the author. According to the present observations, the ultrastructure of bile-duct epithelial cells in cattle does not differ greatly from that in small rodents (Yamada 1969, Rahko 1971), except that in the main bile ducts of cattle goblet cells and mucin-producing glands are frequent and glycogen granules are lacking in the epithelial cells.

In a previous study dealing with the epidemiology of fascioliasis in Finland the author (Rahko 1969) showed that immature infections occurred during the period from September to the middle of January, while the highest numbers of adult flukes were found from January to March. To avoid the immature infections, the present material was collected during February and March, but it proved to be heterogeneous regarding the number of adult flukes and the nature of alterations in the bileduct walls.

Fig u r e 3. Luminal surface of two epithelial cells devoid of regular microvilli in the surface epithelium of the common bile duct. The space between the cells and the intercellular connections are normal.

BL: Lumen of bile duct. $\times \mathbf{1 0 , 0 0 0}$.

Figure 4. Traumatized epithelial cell (arrow) in the surface epithelium of a main intrahepatic bile duct invaded by the flukes. The cell membrane at the luminal surface has been ruptured and the cyto-

plasm of the cell is flowing into the lumen of the duct. $\times 8,000$.

Figure 5. Superficial epithelial cells in the main bile duct may show degenerative changes during the recovery phase of fascioliasis. Some of the electron-opaque bodies are mucin granules and the others probably lysosomes or lipoidal bodies, which are not normally seen. 

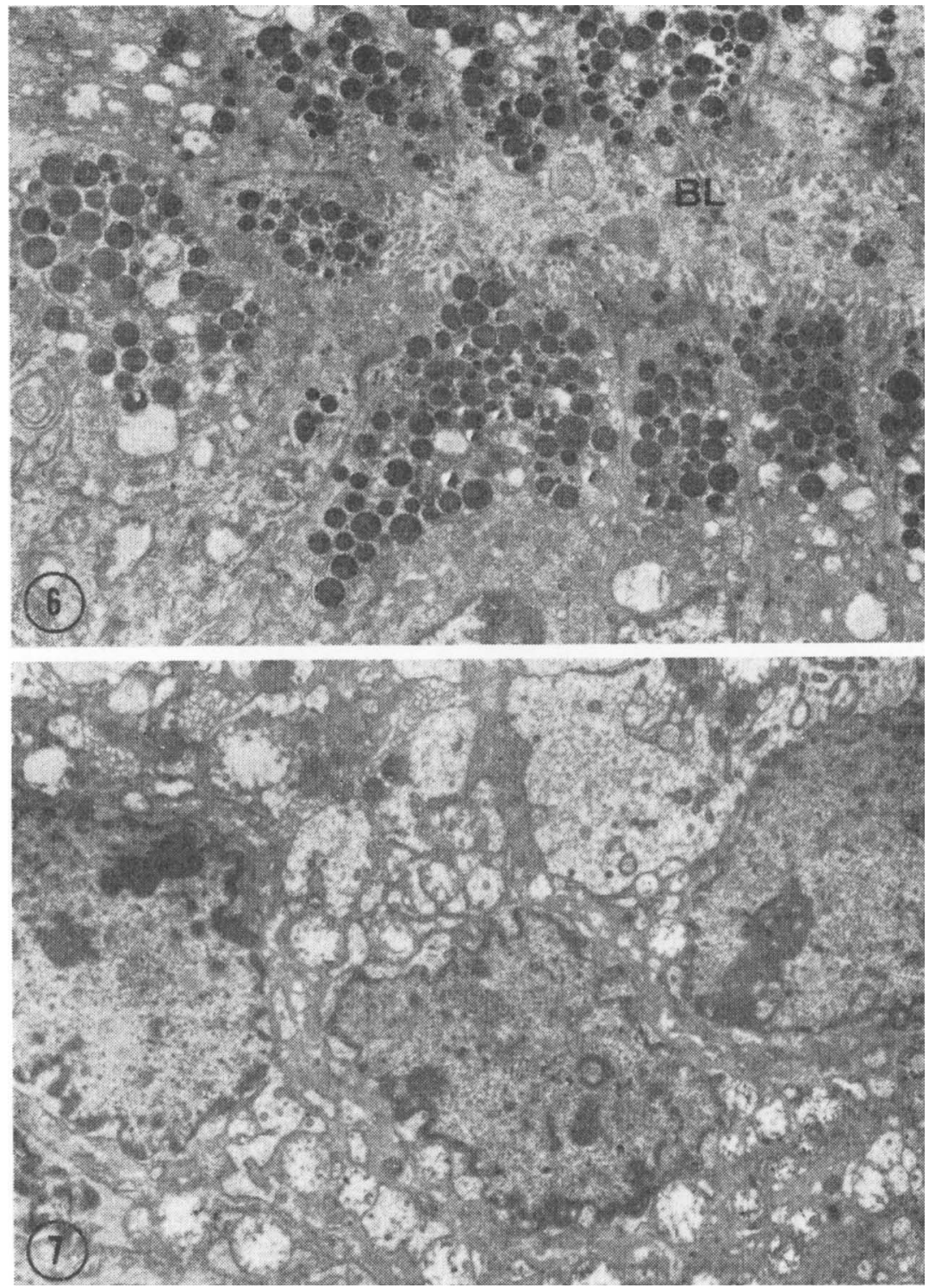

Figure 6. The glandular tissue proliferating in even small bile ducts during chronic fascioliasis is ultrastructurally fairly similar to that normally present only in the largest intrahepatic and the common bile ducts (see Fig. 2). $\times 8,000$.

Fig u re 7. Pronounced alterations are seen in the ultrastructure of epithelial cells in the main bile ducts of heavily infected livers. Note the irregularities in the appearance of also the nuclei of the cells. $\times 8,000$. 
Pathological changes produced by F. hepatica in the bile-duct walls of cattle can be divided into three main histological patterns, which evidently represent chronologically different phases in the pathogenesis of chronic fascioliasis (Rahko 1971). The first histological pattern is characterized by a progressive increase in the amount of epithelial tissues and in their mucin production. In the second histological pattern deep erosions are produced by the flukes in the hyperplastic epithelium. This is followed by a pronounced fibrous reaction and calcification of the walls, possibly leading to a recovery phase, during which the third histological pattern is observed (Rahko 1971).

Light microscopy revealed the first histological pattern in the common bile duct, which is not invaded by flukes in fascioliasis in cattle (Rahko 1971). In the present study changes produced by fascioliasis in the epithelium of the common bile duct were observed to be slight also at ultrastructural level, and the irregularities revealed probably resulted from the increased proliferation of the epithelial cells.

During chronic fascioliasis in cattle the infection level is decisive regarding the severity of clinical symptoms (Sinclair 1967, Boray 1969). The degree and the phase of the infection also influences the nature of the histological alterations present in the liver and bile-duct walls. This was shown by light microscopical studies, which revealed that during chronic fascioliasis in cattle the liver parenchymal cells degenerate only in heavily infected livers, and pronounced changes are then seen in the bile-duct walls (Rahko 1969, 1970, 1971). The results obtained with light microscopy are confirmed and supplemented by those of the present study, which show that the pathological changes occurring in the bile ducts of cattle during mild infections and the recovery phase are also inconsiderable at ultrastructural level.

In the present material the heavily infected livers showed profound pathological changes in the light microscopical tissue specimens of the main bile ducts. In these livers the ultrastructure of the surface epithelium in bile ducts invaded by flukes was pronouncedly altered, as could be expected on the basis of observations made by electron microscopy on experimentally infected mice (see Rahko 1971; Figs. 25 and 26). In a recent paper Ross et al. (1971) showed analogous ultrastructural abnormalities in the abomasal mucosa of calves experimentally 

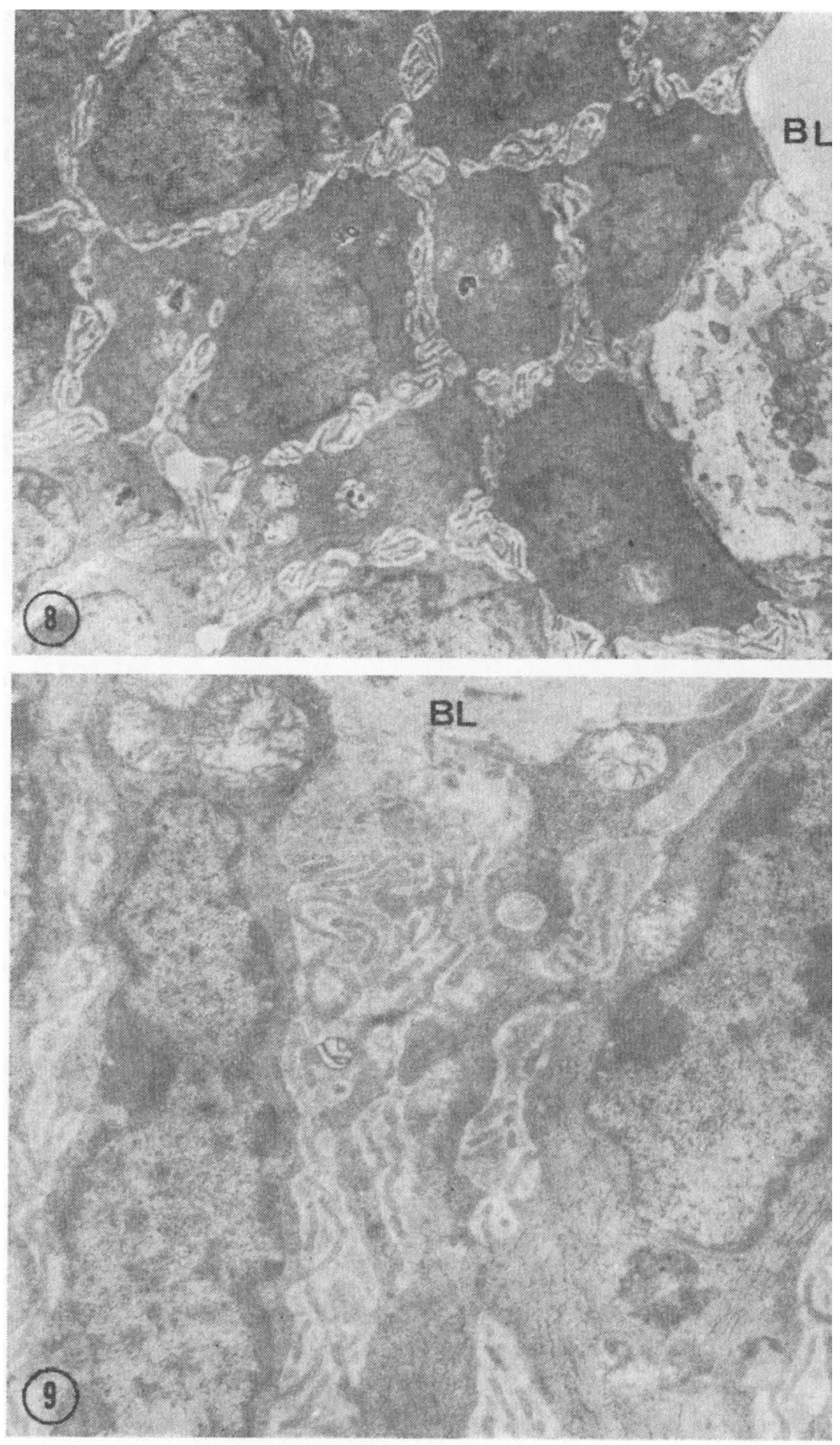
infected with Trichostrongylus axei. They considered that the dense material was albumin, leaking into the intestinal lumen through breaches in the intercellular connections, and suggested that their findings were important in respect to the origin of hypoalbuminaemia associated with gastro-intestinal parasitic diseases.

The appearance of the dense extracellular material in the bile-duct epithelium of cattle and mice (Rahko 1971) with chronic fascioliasis was similar to that described by Ross et al. as albumin in the abomasal epithelium of infected calves. The loss of radio-iodinated albumin into the bile during the chronic phase of fascioliasis has been shown both in experimentally infected rabbits (Dargie \& Mulligan 1971) and in spontaneously infected cattle (Nansen 1971). Nansen also established that infected cattle had a normal or only slightly decreased synthetic rate of albumin in the liver. Accordingly, it seems justifiable to suggest that the foreign extracellular material described by the present author in the bile-duct epithelium of chronically infected cattle and the mouse is probably mainly or exclusively composed of albumin, the leakage of which through ruptured intercellular connections into the bile may contribute to the development of hypoalbuminaemia during chronic fascioliasis.

\section{REFERENCES}

Boray, J. C.: Experimental fascioliasis in Australia. Adv. Parasitol. $1969,7,95-210$.

Dargie, J. D. \& W. Mulligan: Ferrokinetic studies on normal and fluke-infected rabbits. J. comp. Path. 1970, 80, 37-45.

Dargie, J. D. \& W. Mulligan: The onset and development of anaemia and hypoalbuminaemia in rabbits infected with Fasciola hepatica. J. comp. Path. 1971, 81, 187-202.

Dargie, J. D., P. H. Holmes, I. M. McLean \& W. Mulligan: Pathophysiology of fascioliasis in the rabbit. Studies on albumin turnover. J. comp. Path. 1968, 78, 101-105.

F i g u r e 8. Irregular network of superficial epithelial cells is seen in an area harbouring flukes. The intercellular spaces are dilated and filled with dense homogeneous material. The junctional complexes are not intact. $\times 4,800$.

Fig u re 9. Detail from an area corresponding to that in preceding figure, showing the appearance of the foreign material in an intercellular space, which is not sealed off from the lumen by a junctional complex. $\times 12,000$. 
Dawes, B. \& D. L. Hughes: Fascioliasis: The invasive stages in mammals. Adv. Parasitol. 1970, 8, 259-274.

Kay, D.: Techniques for Electron Microscopy. Blackwell Scientific Publications, Oxford 1965.

Luft, J. H.: Improvements in epoxy resin embedding methods. J. biophys. biochem. Cytol. 1961, 9, 409-414.

Nansen, P.: Albumin metabolism in chronic Fasciola hepatica infections of cattle. Acta vet. scand. 1971, 12, 335-343.

Rahko, T.: The pathology of natural Fasciola hepatica infection in cattle. Path. Vet. 1969, 6, 244-256.

Rahko, T.: The hepatic pathology of spontaneous fascioliasis in cattle. Nytt Mag. Zool. 1970, 18, 109-110.

Rahko, T.: Studies on the pathology of bovine and murine liver infected with Fasciola hepatica with reference to the mast cell and globule leucocyte. Ann. Acad. Sci. fenn. A 5 1971, 148, 162 (Thesis).

Ross, J. G., J. McCracken \& D. A. Purcell: The ultrastructural changes in the abomasal mucosa of calves experimentally infected with Trichostrongylus axei. J. Helminth. 1971, 45, 1-9.

Setoguti, T.: Electron microscopic study on the newt mast cell, especially its granule-extrusion mechanism. J. Ultrastruct. Res. $1969,27,377-395$.

Sinclair, K. B.: Pathogenesis of Fasciola and other liver-flukes. Helminth. Abstr. 1967, 36, 115-134.

Yamada, $K$.: Fine structure of rodent common bile duct epithelium. J. Anat. (Lond.) 1969, 105, 511-523.

\section{SAMMANFATTNING}

Gallgångsepitelets ultrastruktur hos nötkreatur med kronisk infektion av Fasciola hepatica.

Detta arbete beskriver i korthet den normala ultrastrukturen och de ultrastrukturella förändringarna i gallgångsepitelet hos nötkreatur, förorsakade av en kronisk infektion med Fasciola hepatica. Vid en lindrig infektion och under sjukdomens läkningsstadium kunde endast obetydliga ultrastrukturella abnormaliteter i epitelet konstateras. Vid en höggradig infektion i levern var däremot de ultrastrukturella förändringarna $\mathrm{i}$ ytepitelet $\mathrm{i}$ de större intrahepatiska gallgångarna, invaderade av leverflundror, mycket påtagliga. I sådana områden var det intercellulära rummet fyllt av ett tätt homogent material. Intakta desmosomer och junktionala komplex kunde endast oregelbundet iakttagas vilket tyder på att ett läkage av främmande material till gallan kan ske. Det extracellulära materialet bestod antagligen av albumin. De anförda resultatens betydelse med avseende på etiologin av hypoalbuminämin i samband med kronisk fascioliasis diskuteras.

(Received January 20, 1972).

Reprints may be requested from: Timo Rahko, Department of Pathology, College of Veterinary Medicine, Hämeentie 57, 00550 Helsinki 55, Finland. 